\section{AN EPIDEMIOLOGIC STUDY OF ACUTE CORONARY SYNDROME IN THE WORKING POPULATION}

1,2 Po-Ching Chu, 1,2 Yue Leon Guo, 1,2 Jyh-Ming Juang. 'National Taiwan University College of Medicine, Taipei, Taiwan; 'National Taiwan University Hospital, Taipei, Taiwan

\subsection{6/oemed-2014-102362.335}

Objectives Some of cardiovascular diseases, like stroke and acute coronary syndrome (ACS), are compensable diseases in Taiwan as well as Japan and Korea. The number of compensated cases in the disease has increased from 13 in 2006 to 92 in 2012. The information on workplace risk factors before onset of disease is rare, and this aim of this study is to conduct a case control study for analysing the association between ACS and work stress, using hospital-based study.

Method The study population was the patients in a medical centre. Questionnaire was designed based on literatures about non-work-related and work-related risk factors of cardiovascular diseases. The work-related factors included working time, working pattern, burnout scale, mental stress. The inclusion criteria of case group were workers more than 20 year-old, diagnosed with acute coronary syndrome and having job at onset. The inclusion criteria of control group were diagnosed without acute coronary syndrome and having job at recruitment.

Results There were 47 cases and 121 controls recruited. The results shows case group had larger percentage of male, alcohol intake, no intake of any healthy diet, and higher education level than control group. In addition, family history of premature AMI, history of diabetes, and history of current URI were more prevalent in case group. Multivariate logistic regression shows that smoking and night work were statistical significant factors associated with occurrence of acute coronary syndrome $(\mathrm{OR}=6.11,3.59)$

Conclusions When we think about the strategy on preventing cardiovascular diseases for working population, work-related factor, like night work, should be considering.

\section{BIOMECHANICAL COMPARISON OF LUMBAR RISK ASSESSMENT IN MANUAL MATERIAL HANDLING WORK}

${ }^{1}$ Kyoosang Kim, ${ }^{2}$ Dongkyeong Lee, ${ }^{3}$ Day Sung Kim. ' Seoul Medical Center, Seoul, Republic of Korea; ${ }^{2}$ Occpational Safety and Health Training Institute, Korea Occupational Safety and Health Agency, Incheon, Republic of Korea; ${ }^{3}$ Occpational Safety and Health Research Institute, Korea Occupational Safety and Health Agency, Incheon, Republic of Korea

\subsection{6/oemed-2014-102362.336}

Objectives In this study, lifting index (LI) by NIOSH lifting equation (NLE) and biomechanical load by lumbar motion monitor (LMM) were determined to assess low-back disorder (LBD) risk associated with manual material handling $(\mathrm{MMH})$ task in manufacturing workers.

Method Thirty-five (28 male and 7 female) workers in 13 $\mathrm{MMH}$ processes in 6 manufacturing companies were investigated. For each worker, LMM measurement and video recording were done simultaneously for $30 \mathrm{~min}$, and LBD risk probability and LI based on recommended weight limit (RWL) were calculated using NLE.

Results Biomechanical load assessment related with lumbar risk assessment in $\mathrm{MMH}$ workers enabled us to identify risks by task characteristics. However, degree of risk of tasks appeared different by assessment tool.
Conclusions Application of assessment tools suitable to work situation is needed. There may be also problems arising from application of foreign assessment tools to Korean workers, and future studies are warranted.

\section{WORKERS' HEALTH OUTCOMES, WORK ORGANISATION AND VIOLENCE FACTORS. ARGENTINA, 2012}

Cecilia Ines Cornelio, Maria Martha Sapoznik, Alfredo Esteban, Marcos Alberto, Adela Contreras, Brian Covaro, Johanna Gerke, Maria Jose Iñiguez. Superintendence of Labour Risk, Buenos Aires, Argentina

\subsection{6/oemed-2014-102362.337}

Objectives To evaluate workers' health outcomes and their association with work organisation (WOF) and violence (WV) factors among sectors of the economy in Argentina.

Method We used data from the first Employment, Working conditions and Health Survey with face-to-face interviews. We selected 7200 sample cases representative of 3000000 workers from different economic sectors across Argentina. Multi-stage methods were applied. Sex and age were considered. The dependent variables were: reported work-injuries, occupational disease, health care visits and symptoms from the workers' perspective. Psychosocial factors were classified as: work organisation factors, violence and harassment factors. To determine the association between health outcomes and risk factors, prevalence and Odds Ratios with 95\% confidence intervals (OR) were estimated using and Logistic Regression.

Results Exposed workers to WOF and WV had highest prevalence of injuries (18\%, $17 \%$ vs. 9 and $11 \%)$, diseases $(6.6,7.5 \%$ vs. 3.5 y $3.8 \%)$ and health care visits, for both WOF and WF respectively $(p<0.001)$. Related symptoms, cardiovascular, gastrointestinal were more expressed in exposed men, OR 1.20, 1.13-1.26; in women the risk of having symptoms were 2 times more compared to non-exposed ones (OR 2.10; 1.93-2.28). Exposed workers to both factors WOF and WV, increased 2-3 times the risk of having health outcomes.

Conclusions Is increasing the evidence of health outcomes related to work organisation factors, therefore, for designing and targeting preventive strategies, and for a comprehensive understanding of health outcomes in the working population, it is necessary to include variables from a psychosocial and gender point of view.

\section{ERYTHROCYTOSIS AND NEUROPSYCHOLOGICAL ALTERATIONS BY CHRONIC EXPOSURE TO LOW CONCENTRATIONS OF CARBON MONOXIDE IN HIGHWAY WORKERS OF MEXICO}

1 'Luis Fernando Díaz López, ${ }^{2,3}$ Luis Cuauhtémoc Haro Garcia, ${ }^{4}$ Guadalupe Aguilar Madrid, ${ }^{4}$ Cuauhtémoc Arturo Juárez Pérez. ${ }^{1}$ Psychiatric Hospital Fray Bernardino Alvarez, Distrito Federal, Mexico: ${ }^{2}$ Department of Public Health Universidad Nacional Autonoma de Mexico, Distrito Federal, Mexico; ${ }^{3}$ Community Health Academy Universidad Autonoma de La Ciudad de Mexico, Distrito Federal, Mexico; ${ }^{4}$ Research Unit Work Health and Safety Centro Medico Siglo XXI, Distrito Federal, Mexico

\subsection{6/oemed-2014-102362.338}

Objectives Identify erythrocytosis and neuropsychological alterations in highway workers exposed chronically to low concentrations of $\mathrm{CO}$ 